\title{
CrystEngComm
}

Check for updates

Cite this: CrystEngComm, 2018, 20, 4436

Received 25th May 2018,

Accepted 1st July 2018

DOI: $10.1039 / \mathrm{c} 8 \mathrm{ce} 00872 \mathrm{~h}$

rsc.li/crystengcomm

\section{Crystalline structure of an ammonia borane- polyethylene oxide cocrystal: a material investigated for its hydrogen storage potential $\dagger$}

\author{
Anna R. Ploszajski, (D)*a Matthew Billing, (iD ${ }^{a}$ Jeremy K. Cockcroft (iD ${ }^{a}$ and \\ Neal T. Skipper (iD ${ }^{b}$
}

\begin{abstract}
The crystalline structure of a cocrystal comprising ammonia borane (AB) and a short-chain polyethylene oxide (PEO or PEG) has been determined by single-crystal $\mathrm{X}$-ray diffraction. The components interact via hydrogen bonds between each of the hydrogen atoms at the $\mathrm{NH}_{3}$ end of the $\mathrm{AB}$ molecules and alternate oxygen atoms along the PEO backbone. The PEO chains in the structure exhibit an unusual conformation where their curvature reverses every 5 monomers, such that the polymer snakes through the crystal. This is the first time that an $\mathrm{AB}$ composite material has been determined to be a cocrystal, and no structure determination of a cocrystal to confine $\mathrm{AB}$ has been reported before.
\end{abstract}

\section{Introduction}

Ammonia borane $(\mathrm{AB}), \mathrm{NH}_{3} \mathrm{BH}_{3}$, is widely recognised as a leading hydrogen storage material. By weight, $\mathrm{AB}$ is rich in hydrogen (19.6 $\mathrm{wt} \% \mathrm{H}_{2}$ ) and, coupled with low dehydrogenation temperatures and promising recycling routes, ${ }^{1}$ it is clear to see why it has become a particularly attractive material for the study of mobile hydrogen-powered applications. However, the implementation of $\mathrm{AB}$ as a hydrogen storage material has been hindered by the presence of an incubation period prior to hydrogen release, foaming during hydrogen release, and the production of volatile by-products such as ammonia, diborane, and borazine, which poison the sensitive catalysts in hydrogen fuel cells.

To improve the hydrogen release characteristics of $\mathrm{AB}$, researchers have successfully used nanostructuring and nanoconfinement techniques ${ }^{2-8}$ as well as chemical additives such as metal-containing ${ }^{9-15}$ and non-metal-containing ${ }^{16-21}$ species. Polymer composites are a particularly attractive option to implement these approaches, since polymers can be cheap and lightweight. To date, poly(methyl acrylate) ${ }^{22}$ poly(methyl methacrylate), ${ }^{23}$ poly(vinyl pyrrolidone $)^{24}$ and polyacrylamide ${ }^{25}$ composites have been successfully produced with $\mathrm{AB}$. These

\footnotetext{
${ }^{a}$ Department of Chemistry, Christopher Ingold Laboratories, UCL, 20 Gordon Street, London WC1H 0AJ, UK. E-mail: anna.ploszajski.13@ucl.ac.uk

${ }^{b}$ The London Centre for Nanotechnology, 17-19 Gordon Street, London, WC1H $O A H, U K$

$\dagger$ Electronic supplementary information (ESI) available: Additional experimental detail, crystallographic tables, and additional supporting figures are supplied. CIF files have been deposited at the Cambridge Crystallographic Data Centre with REFCODES 1844761 (150 K) and 1844762 (295 K). For ESI and crystallographic data in CIF or other electronic format see DOI: 10.1039/c8ce00872h
}

materials combine confinement effects and chemical interactions between $\mathrm{AB}$ and oxygen-containing functional groups within the polymer to improve the properties of the hydrogen storage material.

Cocrystals are unique crystalline arrangements of two or more molecular components with a fixed stoichiometry and properties which differ from those of the parent species. The components interact via weak non-covalent interactions such as hydrogen bonding, van der Waals or electrostatic forces. ${ }^{26}$ Polyethylene oxide (PEO) is a polymer known to form stable cocrystals with various other molecules including pharmaceutical APIs: 2-methyl-resorcinol, ${ }^{27,28} p$-dibromobenzene, ${ }^{29}$ mercuric chloride, ${ }^{30,31}$ resorcinol, ${ }^{32,33} p$-nitrophenol, ${ }^{34}$ hydroquinone, ${ }^{35} p$-dihalogenobenzene, ${ }^{36}$ various isomers and derivatives of dihydroxybenzene, ${ }^{37}$ urea and thiourea, ${ }^{38}$ griseofulvin $^{39}$ and vancomycin. ${ }^{40}$ The molecular weight of PEO used in these studies has ranged from $2000 \mathrm{Da}$ (ref. 33) (frequently known as polyethylene glycol or PEG for MW less than $20000 \mathrm{Da}$ ) to 5000000 $\mathrm{Da}^{29}$ and the host-guest interactions have been shown to be electrostatic, hydrogen-bonds or van der Waals forces. ${ }^{27}$

This paper reports the structure of a cocrystal comprising $\mathrm{AB}$ with short-chain PEO showing a novel conformation of molecular assembly for PEO chains. This combination was discovered when investigating a range of AB-PEO composites for hydrogen storage applications. ${ }^{41,42}$ The combined effect of chemical interactions and physical confinement in cocrystals has potential for modifying the hydrogen release characteristics of $\mathrm{AB}$. The crystal structure represents the first in polymer-based solid-state cocrystals for potential use in hydrogen storage. Indeed, a search of the Cambridge Crystallographic Database showed no examples of cocrystal structures with PEO chain lengths greater than 12 monomers. 


\section{Results and discussion}

The crystals obtained exhibit the morphology of thin, truncated oval-shaped platelets (Fig. 1 and S1 ${ }^{\dagger}$ ). The motif in the unit cell (Fig. 2) resembles a 5-oxygen crown-ether curved around the nitrogen-end of an $\mathrm{AB}$ molecule, with a hydrogen bond between each of the protic hydrogen atoms at this end and alternate oxygen atoms on the PEO backbone. This makes the ratio of PEO monomer (EO) to $\mathrm{AB}$ molecular ratio $5: 1$. This molecular arrangement matches the DFT-predicted geometries of $\mathrm{AB}$ with tetraethylene glycol dimethyl ether (AB.T4EGDE), which was found to be an effective promoter of $\mathrm{AB}$ dehydrogenation. ${ }^{43}$ Given the molecular weight of 1500 Da used here, the mean PEO backbone length is around 34 ethylene oxide $\left(-\mathrm{CH}_{2} \mathrm{CH}_{2} \mathrm{O}-\right)$ units. The $5: 1$ ratio of $-\mathrm{CH}_{2} \mathrm{CH}_{2} \mathrm{O}$ - to $\mathrm{AB}$ within the crystal makes the average cocrystal formula $\left(\mathrm{BH}_{3} \mathrm{NH}_{3}\right)_{7}\left(\mathrm{CH}_{2} \mathrm{CH}_{2} \mathrm{O}\right)_{35}$ (Fig. 3), or 12.3 $\mathrm{wt} \% \mathrm{AB}$. This makes the overall gravimetric density of releasable hydrogen in this material $2.41 \mathrm{wt} \%$.

The cocrystal forms a monoclinic crystal structure in space group $P 2_{1} / n$, with unit cell dimensions $a=8.42518(12) \AA, b=$ 8.39871(16) $\AA, c=20.2469(3) \AA, \alpha=90^{\circ}, \beta=91.5852(13)^{\circ}, \gamma=$ $90^{\circ}, V=1432.13(4) \AA^{3}$ at $150 \mathrm{~K}$. Tables of crystallographic coordinates and molecular geometry are provided in the ESI $\dagger$ (Tables S1-S6).

Previous work on composites of $\mathrm{AB}$ and PEO found that a new crystalline phase is formed when $\mathrm{AB}$ and a high molecular weight PEO (2000000 Da) are combined using both coelectrospinning ${ }^{41}$ or freeze-drying ${ }^{42}$ methods of production. The calculated powder X-ray diffraction pattern of the cocrystals in the current work (Fig. S2 $\dagger$ ) differs from that of this previously observed crystalline material, ${ }^{42}$ indicating that the AB-PEO system has the capability of forming different polymorphs. Unfortunately, the crystallite sizes of the other unknown crystalline form have been very small, so it has not been possible to isolate them for single-crystal analysis (Fig. S3†). Polymorphism has been observed in other PEO-guest cocrystals, for example in the PEO-2-methyl resorcinol system, ${ }^{28}$ stable cocrystals exist for PEO: guest molecular ratios

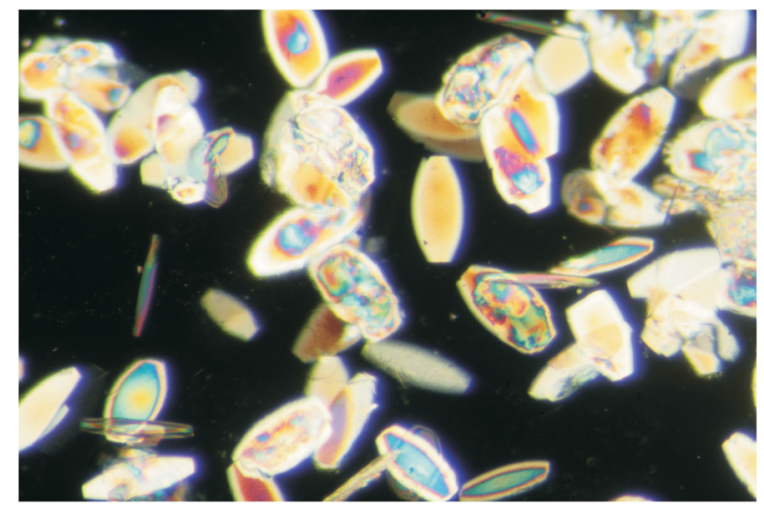

Fig. 1 Polarised optical light microscopy image of the cocrystal of $A B$ with PEO showing the characteristic thin-platelet morphology. Typical crystal size seen here is $300 \times 100 \times 25 \mu \mathrm{m}$.

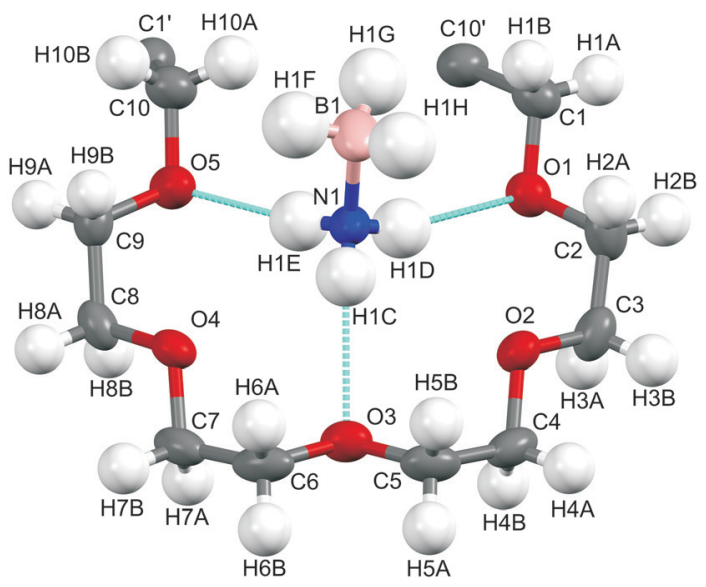

Fig. 2 Crystallographic asymmetric motif of the cocrystal showing the labelling of the atoms and the hydrogen bonding between the ammonia and alternate oxygen atoms within a loop along the backbone chain of the polymer. Thermal ellipsoids are shown at $50 \%$ probability for the structure at $150 \mathrm{~K}$.

of $7: 2$ and $2: 1$. The polymorphism observed for AB-PEO materials is a highly promising prospect for the discovery of interesting new cocrystals for hydrogen storage.

The nature of the interaction between host and guest molecules in cocrystals dictates how they can form; intercalation of a guest molecule by diffusion into the host unit cell is possible for components which interact with weak van der Waals or electrostatic interactions. However, for stronger hydrogen bonding interactions, cocrystals can only form when the host unit cell is destroyed by melting or dissolution and the cocrystal re-crystallised from the melt or solution. ${ }^{27}$ This method of formation of cocrystals occurs in the AB-PEO system; the structure reported herein formed via a melt at the interface of the two parent powders at room temperature, due to a so-called submerged eutectic. ${ }^{26}$ The other AB-PEO polymorph has also been produced successfully by this method using the same and higher molecular weight PEO, and also by solution methods in co-electrospinning ${ }^{41}$ and freeze-drying processes. ${ }^{42}$

The PEO chain confirmation in this cocrystal structure is unusual. In pure PEO, PEO chains are observed to occur in $7_{2}$ helices - seven turns every two unit cells - along the $c$ axis. ${ }^{44}$

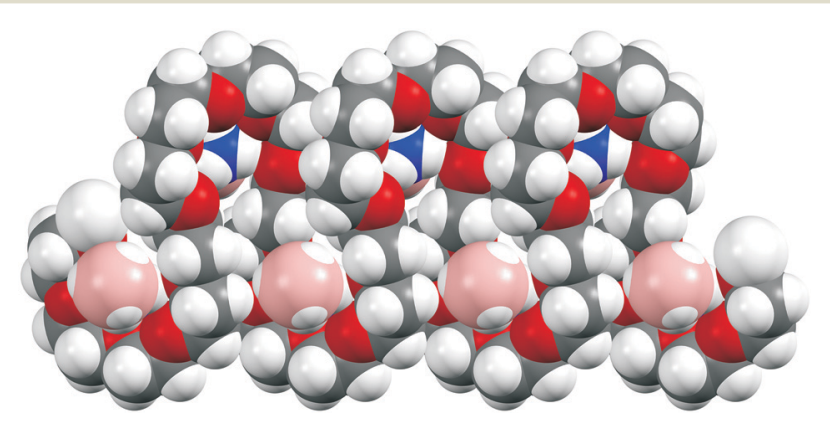

Fig. 3 Space-filling representation of an average cocrystal molecule $\left(\mathrm{BH}_{3} \mathrm{NH}_{3}\right)_{7}\left(\mathrm{CH}_{2} \mathrm{CH}_{2} \mathrm{O}\right)_{35}$ showing the snake-like coils of the polymer structure. 
PEO molecules have also been observed to adopt a planar zigzag modification when stretched. $^{45}$ In PEO-containing cocrystals, the PEO chain confirmations are more varied, for example $7_{2},{ }^{28} 4_{1}$ (ref. 28, 32, 33 and 35) and $10_{3}$ (ref. 46) helices have been reported, as well as more elaborate trans-gauche patterns. $^{30,31,34,47}$ Unusual conformations of PEO have also been seen in battery materials, ${ }^{48-50}$ e.g. $\left(-\mathrm{CH}_{2} \mathrm{CH}_{2} \mathrm{O}-\right)_{9}\left(\mathrm{LiAsF}_{6}\right)_{2}$ in which the $\mathrm{Li}^{+}$is coordinated by the $\mathrm{O}$ atoms in a folded polymer chain.

Herein, the reported cocrystal motif (Fig. 2) involves 5 PEO monomers per $\mathrm{AB}$ molecule. The symmetry of the crystal is such that the curvature of the PEO molecule reverses in adjacent motifs, meaning the polymer molecules snake through the structure (Fig. 4). Starting from the C1 atom, the PEO chain conformation pattern is [t-gt $t+g t t-g t t+g t x t t]$, where $x$ is $-110^{\circ}$. This last group of three torsion angles is the pattern which allows for the reversal of curvature of the next section of the crystal motif. The full table of torsion angles may be found in the ESI, $\uparrow$ Table S6. To our knowledge, a conformation pattern like this has not been seen in other PEO cocrystals.

The polymer chains lie along the $b$ direction within the crystal structure and form sheets within the $a b$-plane that stack along $c$ (Fig. 4). The interactions along $c$ are very weak, and consequently crystals are expected to be very thin along

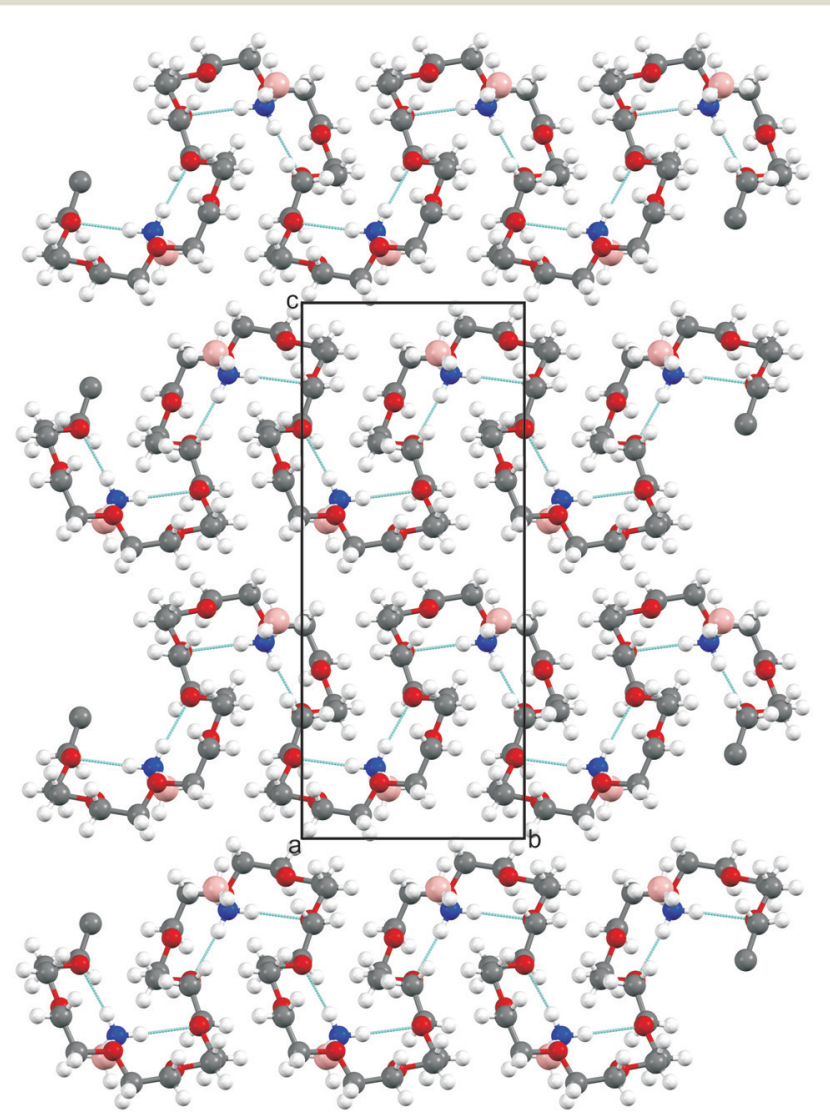

Fig. 4 View of the crystal structure seen down a. There is no hydrogen bonding with respect to the $c$ direction and so interactions between the molecular sheets in this direction will be very weak. this direction (Fig. 1). The $\mathrm{B}-\mathrm{N}$ bond distance in the crystal is 1.594(3) A. This compares to the literature value of 1.58(2) $\AA$ in the orthorhombic $\mathrm{AB}$ crystal measured at $200 \mathrm{~K}$ and 1.597(3) A in the tetragonal phase, both from neutron diffraction. ${ }^{51,52}$ Within the errors of measurement, it is not possible to say whether coordination with PEO in the cocrystal results in a change in the $\mathrm{B}-\mathrm{N}$ bond length compared to $\mathrm{AB}$ crystals, although it might be expected to increase in length due to the presence of the hydrogen bonds, as predicted by DFT calculations. $^{43}$

\section{Conclusions}

This is the first reported crystal structure of an AB-PEO cocrystal. Unusually, the PEO chain bends around the $\mathrm{NH}_{3}$ end of the $\mathrm{AB}$ molecule, with one hydrogen bond per protic hydrogen atom bonding to alternate oxygen atoms on the PEO backbone. Previous work ${ }^{42}$ has shown that the combination of high molecular weight $\mathrm{PEO}$ with $\mathrm{AB}$ produces a cocrystal phase with a lower melting temperature than either of the two parent components and considerably reduced hydrogen release temperatures compared to pure $\mathrm{AB}$. The improvement in the performance of these composites has been attributed to the enhanced rates of the dehydrogenation reaction pathways facilitated by the hydrogen bonding found in the cocrystal. However, this reported cocrystal contains a relatively low gravimetric density of releasable hydrogen compared to US Department of Energy's target for on-board hydrogen storage systems. ${ }^{53}$ Nevertheless, the crystal engineering of polymer-based cocrystals represents an interesting new tool in the researcher's toolbox for finding novel materials for energy storage applications.

\section{Experimental}

PEO with molecular weight 1500 Da (CAS number 25322-68-3, Sigma Aldrich) and $\mathrm{AB}$ (97\%, Boron Specialities) were used without further purification. Powder samples of each (approx. $0.1 \mathrm{~g}$ ) were placed adjacent on a glass microscope slide and left to interact under ambient conditions. Upon checking the slide after 10 months, single crystals were clearly evident using light microscopy in transmission mode with a crosspolarised filter (Fig. 1). A single crystal was selected and the structure at $150 \mathrm{~K}$ was determined using an Agilent SuperNova diffractometer. To permit direct comparisons with ambient powder X-ray diffraction data, a second crystal was selected several weeks later for structure determination at 295 K. Further details of all experiments are available in the ESI. $\dagger$

\section{Conflicts of interest}

There are no conflicts to declare.

\section{Acknowledgements}

The authors are grateful for funding from the EPSRC Centre for Doctoral Training in Molecular Modelling and Materials 
Science (EP/L015862/1) and EPSRC funding of the X-ray diffractometers (EP/K03930X/1).

\section{References}

1 O. T. Summerscales and J. C. Gordon, Dalton Trans., 2013, 42, 10075-10084.

2 A. Gutowska, L. Li, Y. Shin, C. M. Wang, X. S. Li, J. C. Linehan, R. S. Smith, B. D. Kay, B. Schmid, W. Shaw, M. Gutowski and T. Autrey, Angew. Chem., Int. Ed., 2005, 44, 3578-3582.

3 S. Sepehri, A. Feaver, W. J. Shaw, C. J. Howard, Q. Zhang, T. Autrey and G. Cao, J. Phys. Chem. B, 2007, 111, 14285-14289.

4 S. F. Li, Y. H. Guo, W. W. Sun, D. L. Sun and X. B. Yu, J. Phys. Chem. C, 2010, 114, 21885-21890.

5 G. Moussa, S. Bernard, U. B. Demirci, R. Chiriac and P. Miele, Int. J. Hydrogen Energy, 2012, 37, 13437-13445.

6 S.-W. Lai, H.-L. Lin, T. L. Yu, L.-P. Lee and B.-J. Weng, Int. J. Hydrogen Energy, 2012, 37, 14393-14404.

7 Z. Tang, H. Chen, X. Chen, L. Wu and X. Yu, J. Am. Chem. Soc., 2012, 134, 5464-5467.

8 G. Moussa, U. B. Demirci, S. Malo, S. Bernard and P. Miele, J. Mater. Chem. A, 2014, 2, 7717-7722.

9 S. B. Kalidindi, J. Joseph and B. R. Jagirdar, Energy Environ. Sci., 2009, 2, 1274-1276.

10 T. He, Z. Xiong, G. Wu, H. Chu, C. Wu, T. Zhang and Ping Chen, Chem. Mater., 2009, 21, 2315-2318.

11 K. R. Graham, T. Kemmitt and M. E. Bowden, Energy Environ. Sci., 2009, 2, 706-710.

12 H. Wu, W. Zhou, F. E. Pinkerton, M. S. Meyer, G. Srinivas, T. Yildirim, T. J. Udovica and J. J. Rush, J. Mater. Chem., 2010, 20, 6550-6556.

13 Y. Li, F. Fang, Y. Song, Y. Li, Q. Zhang, L. Ouyang, M. Zhu and D. Sun, Int. J. Hydrogen Energy, 2012, 37, 4274-4279.

14 Y. W. Wang and Z. X. Guo, J. Mater. Chem. A, 2014, 2, 6801-6813.

15 I. Dovgaliuk, C. S. Le Duff, K. Robeyns, M. Devillers and Y. Filinchuk, Chem. Mater., 2015, 27, 768-777.

16 D. J. Heldebrant, A. Karkamkar, N. J. Hess, M. Bowden, S. Rassat, F. Zheng, K. Rappe and T. Autrey, Chem. Mater., 2008, 20, 5332-5336.

17 D. W. Himmelberger, L. R. Alden, M. E. Bluhm and L. G. Sneddon, Inorg. Chem., 2009, 48, 9883-9889.

18 A. C. Gangal, R. Edla, K. Iyer, R. Biniwale, M. Vashistha and P. Sharma, Int. J. Hydrogen Energy, 2012, 37, 3712-3718.

19 A. C. Gangal, P. Kale, R. Edla, J. Manna and P. Sharma, Int. J. Hydrogen Energy, 2012, 37, 6741-6748.

20 H. T. Hwang, P. Greenan, S. J. Kim and A. Varma, AIChE Journal, 2013, 59, 405-410.

21 Y. J. Choi, E. C. E. Rönnebro, S. Rassat, A. Karkamkar, G. Maupin, J. Holladay, K. Simmons and K. Brooks, Phys. Chem. Chem. Phys., 2014, 16, 7959-7968.

22 J. Zhao, J. Shi, X. Zhang, F. Cheng, J. Liang, Z. Tao and J. Chen, Adv. Mater., 2010, 22, 394-397.

23 J. Alipour, A. M. Shoushtari and A. Kaflou, J. Mater. Sci., $2015,50,3110-3117$.
24 Z. Tang, S. Li, Z. Yang and X. Yu, J. Mater. Chem., 2011, 21, 14616-14621.

25 S. F. Li, Z. W. Tang, Y. B. Tan and X. B. Yu, J. Phys. Chem. C, 2012, 116, 1544-1549.

26 N. Blagden, D. J. Berry, A. Parkin, H. Javed, A. Ibrahim, P. T. Gavan, L. L. De Matosa and C. C. Seaton, New J. Chem., 2008, 32, 1659-1672.

27 P. Damman, L. Patemostre, J. Moulin and M. Dosiere, Macromol. Symp., 1999, 138, 57-71.

28 L. Paternostre, P. Damman and M. Dosière, Macromolecules, 1999, 32, 153-161.

29 J. J. Point and C. Coutelier, J. Polym. Sci., Polym. Phys. Ed., 1985, 23, 231-239.

30 R. Iwamoto, Y. Saito, H. Ishihara and H. Tadokoro, J. Polym. Sci., Polym. Phys. Ed., 1968, 6, 1509-1525.

31 A. A. Blumberg, S. S. Pollack and C. A. J. Hoeve, J. Polym. Sci., Part A: Gen. Pap., 1964, 2, 2499-2502.

32 E. Delaite, J.-J. Point, P. Damman and M. Dosière, Macromolecules, 1992, 25, 4768-4778.

33 R. M. Myasnikova, E. F. Titova and E. S. Obolonkova, Polymer, 1980, 21, 403-407.

34 J. J. Point and P. Damman, Macromolecules, 1992, 25, 1184-1188.

35 L. Paternostre, P. Damman and M. Dosière, J. Polym. Sci., Part B: Polym. Phys., 1999, 37, 1197-1208.

36 J. J. Point and P. Damman, Macromolecules, 1991, 24, 2019-2023.

37 L. A. Belfiore and E. Ueda, Polymer, 1992, 33, 3833-3840.

38 F. E. Bailey Jr and H. G. France, J. Polym. Sci., 1961, 49, 397-406.

39 Z. Zhong, C. Guo, L. Chen, J. Xu and Y. Huang, Chem. Commun., 2014, 50, 6375-6378.

40 P. J. Loll, A. Derhovanessian, M. V. Shapovalov, J. Kaplan, L. Yang and P. H. Axelsen, J. Mol. Biol., 2009, 385, 200-211.

41 A. S. Nathanson, A. R. Ploszajski, M. Billing, J. P. Cook, D. W. K. Jenkins, T. F. Headen, Z. Kurban, A. Lovell and S. M. Bennington, J. Mater. Chem. A, 2015, 3, 3683-3691.

42 A. R. Ploszajski, M. Billing, A. S. Nathanson, M. Vickers and S. M. Bennington, Int. J. Hydrogen Energy, 2018, 43, 5645-5656.

43 Y. Kim, H. Baek, J. H. Lee, S. Yeo, K. Kim, S.-J. Hwang, B. Eun, S. W. Nam, T.-H. Limac and C. W. Yoon, Phys. Chem. Chem. Phys., 2013, 15, 19584-19594.

44 Y. Takahashi and H. Tadokoro, Macromolecules, 1973, 6, 672-675.

45 Y. Takahashi, I. Sumita and H. Tadokoro, J. Polym. Sci., 1973, 11, 2113-2122.

46 M. Dosiere, Macromol. Symp., 1997, 114, 51-62.

47 Y. Chatani and S. Okamura, Polymer, 1987, 28, 1815-1820.

48 W. A. Henderson, N. R. Brooks and V. G. Young, Jr., J. Am. Chem. Soc., 2003, 125, 12098-12099.

49 E. Staunton, A. M. Christie, Y. G. Andreev, A. M. Z. Slawin and P. G. Bruce, Chem. Commun., 2004, 148-149.

50 C. Zhang, S. J. Lilley, D. Ainsworth, E. Staunton, Y. G. Andreev, A. M. Z. Slawin and P. G. Bruce, Chem. Mater., 2008, 20, 4039-4044. 
51 W. T. Klooster, T. F. Koetzle, P. E. M. Siegbahn, T. B. Richardson and R. H. Crabtree, J. Am. Chem. Soc., 1999, 121, 6337-6343.

52 M. E. Bowden, G. J. Gainsford and W. T. Robinson, Aust. J. Chem., 2007, 60, 149-153.
53 DOE Targets for Onboard Hydrogen Storage Systems for Light-Duty Vehicles https:/www.energy.gov/sites/prod/files/ 2017/05/f34/fcto_myrdd_table_onboard_h2_storage_systems_ doe_targets_ldv_1.pdf (accessed June 2018). 